\title{
NOTE
}

\section{Inexpensive and portable sampler for collecting eggs of free-spawning marine invertebrates underwater}

\author{
Craig A. Styan* \\ Department of Zoology, University of Adeiaide, South Australia 5005, Australia
}

\begin{abstract}
A simple device is described that can be used to collect the eggs of free-spawning marine invertebrates and that is cheap, portable and fool-proof. The air-displacement sampler was used to collect eggs from female sea urchins, Heliocidaris erythrogramma, downstream from experimentally induced spawning males. Average fertilisation rates of eggs decreased downstream and were $87,48,40,17$ and $7 \%$ at $10,100,200,400$ and $1000 \mathrm{~cm}$ respectively.
\end{abstract}

KEY WORDS: Fertilisation ecology Sampling - Sea urchin Heliocidaris - Marine invertebrate

There is increasing evidence that eggs released by free-spawning marine invertebrates and fish are not always successfully fertilised (reviewed in Levitan 1995, Levitan \& Peterson 1995). Predicting when and where incomplete fertilisation is likely to occur is important for the conservation of these species and understanding their evolutionary ecology (Levitan 1995, Levitan \& Peterson 1995). Measurement of fertilisation success in field experimental studies (Pennington 1985, Levitan 1991, Babcock et al. 1994) or direct observations of natural spawning events (Peterson 1991, Babcock \& Mundy 1992, Babcock et al. 1992, Peterson et al. 1992, Sewell \& Levitan 1992, Shapiro et al. 1994. Marconato et al. 1995) require that isolated samples of free-spawned eggs be collected in situ and safely transported back to the laboratory. To facilitate the collection of such data, I describe here a new diveroperated device (the 'air-displacement sampler') that can be used to collect eggs underwater. As a demonstration of its use in the field, I report the results of a simple experiment in which the sampler was used to collect the eggs of female sea urchins (Heliocidaris erythrogramma) that were induced to spawn at vary-

\footnotetext{
•E-mail: cstyan@zoology.adelande.edu.au
}

ing distances downstream from a spawning male. As a broad test of the sampler, it was expected that the results of this experiment would show a pattern of decreasing fertilisation success with increasing distance downstream, similar to that found in previous experimental (Pennington 1985, Levitan 1991, Babcock et al. 1994) and theoretical work (Denny 1988). These data are also likely to be important in their own right, for they are the first indicating the scale (of distance between spawners and hence population density) over which sperm limitation effects may occur in $H$. erythrogramma. For commercially harvested populations of urchins such as $H$. erythrogramma, incorporating 'Allee Effects' (reduced per capita larval production through sperm limitation effects) into population models may be important for effective management (Quinn et al. 1993).

The air-displacement suction sampler. The airdisplacement sampler, shown in Fig. 1, is based upon a 2 l, air filled, clear solid plastic container with a sealable, screw-top lid. The sampler works underwater by drawing water (and eggs) through a lower inlet tap into an attached (empty) plastic bag as air is released from the container through an upper outlet tap (bore of both taps $=19 \mathrm{~mm}$ ). The sampler needs to be held upright (as in Fig. 1B) with both the inlet and outlet taps open for this to occur. Once the plastic bag is full or sufficient numbers of eggs have been collected, the inlet tap is closed, sealing the sample for return to the laboratory, and the bag/lid simply unscrewed.

Taking further samples is a simple process if working in shallow water-the container is simply opened above water (refilling the main container with air) and a new bag/lid attached. Underwater, the main container can be refilled by closing the outlet tap and purging a diver's octopus regulator into it, then screwing a new bag/lid onto the air filled container. Note that the container does not have to be completely filled with air for 


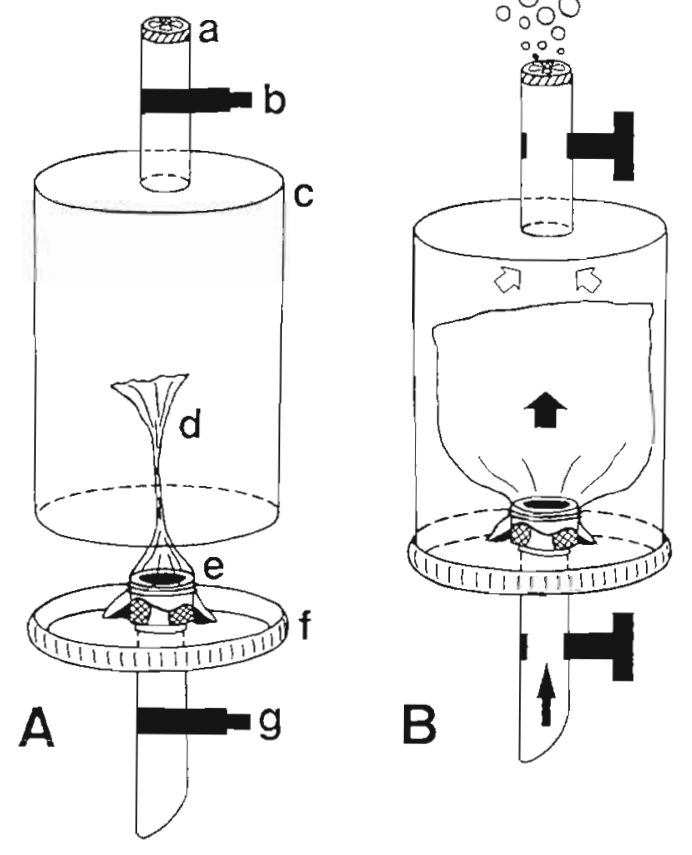

Fig. 1. The air-displacement sampler. (A) Outlet and inlet taps closed. (a) 1-way snorkel valve, (b) outlet tap, (c) 2 l plastic container, (d) plastic bag attached to (e) snap-on garden hose connector, (f) screw on, sealable lid, (g) inlet tap. (B) Outlet and inlet taps open. Air (hollow arrows) escapes from within container through upper one-way valve, drawing eggs and water (solid arrows) through inlet tap into attached internal plastic bag

the sampler to work. If a clear plastic container is used and filled underwater, adjusting air volume within the container to a calibration mark before attaching the bag/lid (by filling then venting excess air through the outlet tap) allows consistent sampling of a fixed, known volume of water (volume of sample $=$ volume of air released). A one-way snorkel valve on the outlet tap allows this tap to be opened without escape of air once the bag/lid is attached, priming the sampler for action. as soon as the inlet tap is also opened. To avoid the bulk of multiple lid/inlet taps, plastic 'snap-on' garden hose connections (Nylex ${ }^{\mathrm{TM}}$ ) can be used to attach replacement plastic bags to a single lid/inlet tap, with plugs and one-way valves within the hose fittings used to seal removed, filled bags

The main features of this sampler are its simplicity and portability. The air-displacement sampler is extremely inexpensive and easy to make. Parts cost less than $A \$ 60$ but most could be found (at no cost) lying around an aquarium or workshop. The other benefit of its extreme simplicity is that it cannot suffer circuit or battery failure, nor can it fail through flooding. The airdisplacement sampler is easily carried and operated by a single worker on SCUBA and the whole sampler, diver's slate and 12 replacement bags can be carried in a. medium sized catchbag that weighs very little above $(<1 \mathrm{~kg})$ or below the water. This is in contrast to some other samplers (e.g. the 'COTSucker'; Mundy et al. 1994)

Fertilisation success of Heliocidaris erythrogramma. Ripe urchins were collected from a shallow subtidal rocky reef at Wool Bay, Yorke Peninsula, South Australia, in late November 1995 and were taken to a nearby site at Edithburgh Jetty where they were induced to spawn by injecting 3 to $5 \mathrm{ml}$ of a $0.5 \mathrm{M} \mathrm{KCl}$ solution into the body cavity. To simulate rocky reef habitat where Heliocidaris erythrogramma are commonly found, rows of $18 \times 18 \times 18 \mathrm{~cm}$ concrete blocks were arranged in line with the prevailing current and a single spawning male was placed on a central block. After 10 minutes of male spawning, a spawning female was placed on the furthermost downstream block and, as they were released, her eggs were collected using the air-displacement sampler. The female was then moved to the next block upstream where a new sample of eggs was collected as released. The female was moved upstream until egg samples had been collected at $1000,400,200,100$ and $10 \mathrm{~cm}$ downstream of the (still spawning) male. An egg sample was also collected $800 \mathrm{~cm}$ upstream of the male, which was assumed to be free of sperm from the experimental male, to act as a control for background fertilisations. All sample bags were filled at the maximum rate (valves fully open). Three hours later, at least 200 eggs per sample were examined under a dissecting microscope and scored for the presence or absence of fertilisation membranes or cleavage lines that indicated successful fertilisation. This was repeated 5 times over 3 consecutive days, using a new pair of ripe urchins each time. Water was $4 \mathrm{~m}$ deep and at $18^{\circ} \mathrm{C}$ and current speeds were between 5 and $12 \mathrm{~cm} \mathrm{~s}^{-1}$.

With valves opened fully, the sampler collected 1.3 I samples of eggs and water at a rate of $31 \mathrm{~min}^{-1}$. Heliocidaris erythrogramma eggs are large (approx. $400 \mu \mathrm{m}$ ), buoyant, often stick together in strings and are a highly visible orange colour and so multiple strings could be collected some distance downstream (up to $1.5 \mathrm{~m}$ ) from the female using several sampling 'sucks' by opening and closing the inlet valve. Eggs remained in good condition in the plastic bags and many hundreds were easily filtered out to be examined later.

Fertilisation success (displayed in Fig. 2) decreased with increasing distance from the male, presumably because of decreasing sperm concentration downstream. The average rates of fertilisation were $87,48,40,17$ and $7 \%$ at $10,100,200,400$ and $1000 \mathrm{~cm}$. downstream respectively. All control samples indicated no background fertilisation during trials. These values are similar, but perhaps slightly greater than, rates found in equivalent field experiments for the urchins Strongylocentrotus 


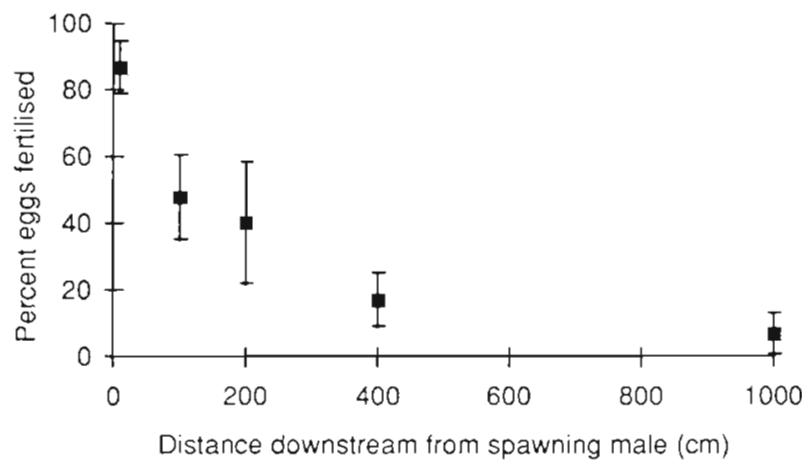

Fig. 2. Mean ( \pm SE) fertilisation success of female Heliocidaris erythrogramma with uncreasing distance downstream from a spawning male $(\mathrm{n}=5)$

droebachiensis (Pennington 1985) and Diadema antillarum (Levitan 1991). Higher fertilisation rates were found over these distances for the crown of thorns starfish Acanthaster planci (Babcock et al. 1994) but much lower rates found for the scallop Chlamys bifrons (Styan unpubl.). That the pattern of the Heliocidaris erythrogramma data fits well within previous estimates tentatively suggests that the air-displacement sampler returns realistic fertilisation estimates, or at least estimates with similar biases to other sampling devices. Assuming no bias, these data also suggest that large Allee Effects are unlikely in populations of $H$. erythrogramma where there is a reasonable likelihood of male spawners within $400 \mathrm{~cm}$ upstream of females. Although it provides an indication of the scale of inter-spawner distance over which sperm limitation may occur, care must be taken in extrapolating data from simple linear arrays to population models of fertilisation success. To be reasonable, such models require further data about sperm dispersal upstream and across current, population dispersion patterns and level of spawning synchrony between individuals (Styan unpubl.)

Any device used to collect free-spawned eggs potentially may bias estimates of fertilisation success (Levi$\tan 1995)$ and at this point it is not possible to determine to what degree the air-displacement sampler has affected the Heliocidaris erythrogramma data. Upwards bias in fertilisation rate may have been caused by containing eggs at high concentrations of sperm for longer than would be experienced otherwise (Morris 1994). However, models of fertilisation kinetics (Vogel et al. 1982, Styan unpubl.) and laboratory experiments (Levitan et al. 1991) indicate that most sperm and egg collisions occur within the first few seconds of exposure of eggs to sperm, suggesting any bias will be slight. Killing contained sperm or removing samples as quickly as possible to the surface where eggs can be washed with/into sperm-free water are probably the best ways to avoid this problem (S. T. Mead \& R. C.
Babcock unpubl.). Collecting eggs as long as possible after spawning should also help to reduce sampling biases associated with preventing eggs from mixing freely in natural conditions, but needs to be weighed against increased difficulty in capturing dilute eggs. Further work is required to determine whether apparent differences in the scale over which fertilisation works that occur between species reflect true differences in the dynamics of external fertilisation or in stead are related to techniques used or environmental conditions experienced during experiments by different workers.

As expected, the sampler worked without failure in all trials and the reasonably large volume of water sampled (1.3 l) allowed capture of an acceptable number of eggs at some distance downstream from the female. The air-displacement sampler can collect much more than the largest presently available plastic syringe $(60 \mathrm{ml}$ ), but other pump/filter samplers (Mundy et al. 1994, Taylor et al. 1995) or Nitex mesh nets (Peterson 1991, Peterson et al. 1992) may be better for sampling barely visible eggs at very low concentrations. Larger samples might be taken with a scaled up version of the air-displacement sampler, but changes in buoyancy associated with the displacement of $>2 \mathrm{l}$ of air may lead to dangerous problems for incorrectly weighted divers. Modifications such as an air collection/recycling container attached to the outlet tap and appropriate weighting with lead may circumvent this, but would negate the primary advantages (size, portability and simplicity) of the air-displacement sampler.

The small construction costs, easy storage and foolproof reliability means that the air-displacement sampler could be easily carried on nearly all field ventures where free-spawning events may be encountered. Given the highly sporadic and unpredictable nature of most sightings of free-spawning events (Pennington 1985, Pearse et al. 1988, Minchin 1992, Babcock \& Mundy 1992, Babcock et al. 1992. Sewell \& Levitan 1992), I would encourage marine ecologists to do this and be ready at all times to add to the regrettably small number of fertilisation rate measurements made during natural spawning events.

Acknowledgements. Joanna Strzelecki and Ian Magraith provided invaluable help in the field and Alan Butler, Joanna Strzelecki, Andy Davis and Michael M. Beck provided comments on this note. I was supported by an Australian Postgraduate Research Award, a Queens Trust Award and a University of Adelaide Alumni Award.

\section{LITERATURE CITED}

Babcock RC, Mundy CN (1992) Reproductive biology, spawning and field fertulization rates of Acanthaster planci. Aust J Mar Froshwat Res 43:525-5.34 
Babcock R, Mundy C, Keesing J, Oliver J (1992) Predictable and unpredictable spawning events: in situ behavioural data from free-spawning coral reef invertebrates. Inv Reprod Develop 22:213-228

Babcock RC, Mundy CN, Whitehead D (1994) Sperm diffusion models and in situ confirmation of long-distance fertilization in the free-spawning asteroid Acanthaster planci. Biol Bull 186:17-28

Denny MW (1988) Biology and mechanics of the wave-swept environment. Princeton University Press, Princeton

Levitan DR (1991) Influence of body size and population density on fertilization success and reproductive output in a free-spawning invertebrate. Biol Bull 181:261-268

Levitan DR (1995) The ecology of fertilization in freespawning invertebrates. In: MCEdward LR (ed) Ecology of marine invertebrate larvae. CRC Press, Boca Raton, p $123-156$

Levitan DR, Peterson CW (1995) Sperm limitation in the sea. TREE 10:228-231

Levitan DR, Sewell MA, Chia FS (1991) Kinetics of fertilization in the sea urchin Strongylocentrotus franciscanus: interaction of gamete dilution, age, and contact time. Biol Bull 181:371-378

Marconato A, Tessari V, Marin G (1995) The mating system of Xyrichthys novacula: sperm economy and fertilization success. J Fish Biol 47: 292-301

Minchin D (1992) Multiple species, mass spawning events in an Irish sea lough: the effect of temperatures on spawning and recruitment of invertebrates. Inv Reprod Develop 22: $229-238$

Morris A (1994) The effect of population parameters on the fertilization success of the asteroid Acanthaster planci (L.), a modelling approach. BSc (Hons) thesis, Dept Zoology,

This note was presented by A. J. Underwood (Senior Editorial Advisor), Sydney, Australla
University of. Queensland, Brisbane

Mundy C, Babcock R, Ashworth I, Small J (1994) A portable, discrete-sampling submersible plankton pump and its use in sampling starfish eggs. Biol Bull 186:168-171

Pearse JS, McClary DJ, Sewell MA, Austin WC, Perez-Ruzafa A, Byrne M (1988) Simultaneous spawning of six species of echinoderms in Barkely Sound, British Columbia. Inv Reprod Develop 14:279-288

Pennington JT (1985) The ecology of fertilization of echinoid eggs: the consequences of sperm dilution, adult aggregation. and synchronous spawning. Biol Bull 169:417-430

Peterson CW (1991) Variation in fertilization rate in the tropical reef fish, Halichoeres bivattatus: correlates and implications. Biol Bull 181:232-237

Peterson CW, Warner RR, Cohen S, Hess HC, Sewell AT (1992) Variable pelagic fertilization success: implications for mate choice and spatial patterns of mating. Ecology 73:391-401

Quinn JF, Wing SR, Botsford LW (1993) Harvest refugia in marine invertebrate fisheries: models and applications to the red sea urchin Strongylocentrotus franciscanus. Am Zool 33:537-550

Sewell MA, Levitan DR (1992) Fertilization success during a natural spawning of the dendrochirote sea cucumber Cucumaria miniata. Bull Mar Sci 51:161.-166

Shapiro DY, Marconato A. Yoshikawa T (1994) Sperm economy in a coral reef fish, Thalassoma bifasciatum. Ecology 75:1334-1344

Taylor RB, Blackburn RI, Evans JH (1995) A portable batterypowered suction device for the quantitative sampling of small benthic invertebrates. J Exp Mar Biol Ecol 194:1-7

Vogel $\mathrm{H}$, Czihak G, Chang P, Meland W (1982) Fertilization kinetics of sea urchin eggs. Math Biosci 58:189-216

Manuscript first received: September 24, 1996

Revised version accepted: March 3, 1997 